\title{
Pemanfaatan Aplikasi Jotform Sebagai Media Request Pengambilan Donasi Pada Sistem ZFord
}

\author{
The Use of Jotform Application as Media Request \\ Donation Decision on Zord System
}

\author{
Untung Rahardja ${ }^{1}$, Indri Handayani ${ }^{2}$, Sarah Riwanda Shofroh ${ }^{3}$ \\ Alumni Universitas Indonesia Program Studi Magister Teknologi Informasi ${ }^{1}$, Dosen Sistem \\ Informasi Perguruan Tinggi Raharja ${ }^{2}$, Mahasiswa STMIK Raharja Jurusan Sistem Informasi ${ }^{3}$ \\ untung@raharja.info1,indri@raharja.info2,sarah.riwanda@raharja.info3
}

\begin{abstract}
Abstrak
Crowdfunding atau penggalangan dana kini merambah ke dunia virtual untuk merealisasikan sebuah project, penggalangan dana dengan mudah dan aman diperlukan demi terealisasinya project. Namun masih terdapatnya beberapa permasalahan yang dihadapi saat ini, mengenai form request untuk pengambilan hasil donasi yang masih dilakukan melalui request email pribadi. Oleh karena itu dengan menerapkan suatu sistem form request untuk pengambilan hasil donasi menggunakan Jotform, sehingga pengguna yang ingin request tidak lagi harus email pribadi sehingga laporan akan tersusun rapih dan jelas. Adapun pengembangan aplikasi ini mengunakan aplikasi Jotform untuk request pengambilan hasil donasi merupakan salah satu sarana form pengajuan dari pengguna ke bagian admin, dimana setelah pengguna mengisi form tersebut terdapat notifikasi email yang telah tertuju ke admin. Hasil dari penelitian ini adalah dimana dapat digunakan users agar lebih mudah dalam merequest pengambilan hasil donasi. Maka dapat disimpulkan bahwa form request pengambilan hasil donasi menggunakan Jotform dapat memaksimalkan pelayanan request dalam menunjang pengambilan hasil donasi.
\end{abstract}

Kata kunci - Crowdfunding, Pengambilan donasi, Jotform, Project, Penggalangan dana

\begin{abstract}
Crowdfunding or fundraising is now venturing into the virtual world to realize a project, fundraising is easy and secure necessary for the realization of the project. But still have a few problems faced today, on the request form for retrieval by donations which are still done through personal email request. Therefore, by applying a system request form for making donations using Jotform results, so users who want to request no longer have a private email so that the report will be arranged neatly and clearly. The development of these applications use the application to request a harvesting Jotform donation is one means of form submission from the user to the admin section, where after a user fills out the form there is an email notification has been drawn to admin. Results from this study is where users can be used for easy retrieval requesting donated. It can be concluded that the request form harvesting donations using Jotform can maximize service request donations to support the retrieval results.
\end{abstract}

Keywords - Crowdfunding, making donations, Jotform, Project, Fundraising

\section{PENDAHULUAN}

Manfaat teknologi informasi dan komunikasi juga dapat dimanfaatkan dalam sistem pengambilan hasil donasi yang terdapat pada sistem ZFord yang dapat memberi 2 (dua) kemudahan untuk pihak pengguna sistem dan admin. Saat ini proses pelayanan untuk request pengambilan hasil donasi yang dilakukan oleh pengguna ke bagian admin yang berjalan, khususnya pada sistem ZFord masih menggunakan request melalui email pribadi pengguna ke admin, sehingga dengan adanya request melalui email pribadi tersebut akan terjadi beberapa langkah seperti menanyakan berapa jumlah donasinya dan menunggu balasan pengguna tersebut dan membutuhkan waktu lama apabila pengguna tersebut tidak aktif dalam email. Dengan 
beberapa langkah manual tersebut tidak memanfaatkan Teknologi Informasi, dimana penjelasan langkah manual tersebut dijelaskan secara detail yang terdapat dalam pembahasan permasalahan karya ilmiah ini. Sistem ZFord akan terus melakukan peningkatan dan pengembangan sistem dengan memberikan kemudahan dalam pelayanan kepada pengguna dalam proses pengajuan pengambilan hasil donasi sebagai pendukung aktivitas admin dengan memanfaatkan aplikasi Jotform dalam membuat form request pengambilan hasil donasi yang dapat diakses secara online dalam web tersebut serta meningkatkan kualitas dengan cara mengembangkan fasilitas yang dapat digunakan secara maksimal. Seperti pada gambar satu berikut ini.

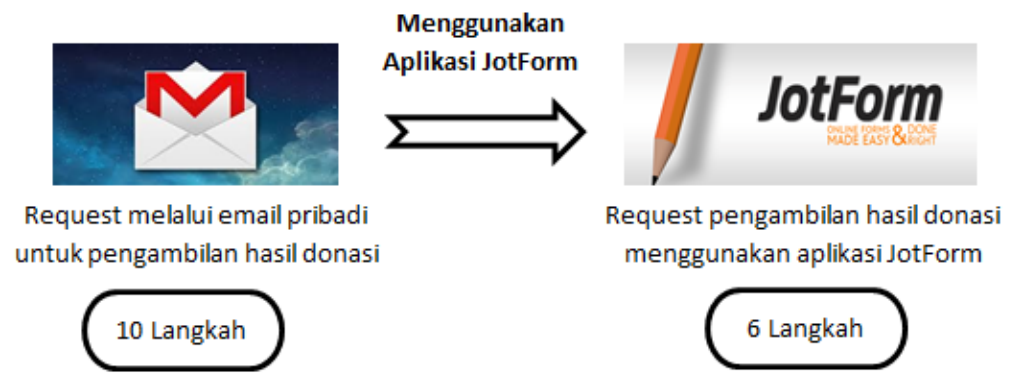

Gambar 1. Transformasi Request Pengambilan Hasil Donasi

Tampak pada gambar satu, menjelaskan transformasi Request pengambilan hasil donasi dengan menggunakan aplikasi JotForm yang dapat merubah alur sistem request yang dilakukan dengan 10 (sepuluh) langkah apabila request melalui email pribadi dan bertransformasi menjadi 6 (enam) langkah apabila request melalui form yang tersedia pada web tersebut, dan form tersebut menggunakan aplikasi JotForm. Form Request ini juga dapat menguntungkan pada bagian admin karena apabila pengguna request admin bisa langsung mengeksekusi permintaan users tersebut.

\subsection{Literature Review}

Beberapa Literature review tersebut adalah sebagai berikut :

1. Penelitian yang dilakukan oleh H Amee, C Isaac dari Wingate University, pada tahun 2015 yang berjudul "I HAVE RESERVATIONS: The Design and Implementation of an Online Library Instruction Form for University Faculty". Penelitian ini menjelaskan perihal akademik pustakawan dirancang untuk perpustakaan online sebagai instruksi reservasi permintaan formulir untuk fakultas. Formulirnya, dibuat menggunakan software JotForm [versi gratis], menyederhanakan proses pemesanan perpustakaan dan membantu fakultas lebih memahami, desain, dan permintaan informasi untuk mahasiswa. [1]

2. Penelitian yang dilakukan oleh DV Birolini, S Rasslan, EM Utiyama dari Universidade de São Paulo (HCFMUSP), SP, Brasil pada tahun 2016 berjudul "Unintentionally retained foreign bodies after surgical procedures. Analysis of 4547 cases". Penelitian ini mejelaskan tentang tujuan untuk mengeksplorasi pengalaman dokter bedah Brasil di Perairan asing Retained Foreign Bodies (RFB) setelah prosedur bedah. Ini adalah crosssectional, studi observasional yang dilakukan dengan cara survei dikembangkan dengan bantuan alat Jotform (www.jotform.com) dan dikirim melalui Internet kepada anggota masyarakat Brasil yang berhubungan dengan spesialisasi Urologi, Ginekologi , Obstetri, General, Oncologic dan Bedah Toraks, Coloproctology, dan Bedah dari pencernaan Saluran dan Trauma. Tanggapan dimana bersifat sukarela, rahasia dan tidak diketahui. [2]

3. Penelitian ini dilakukan oleh AJ Kemppainen, GL Hein, MR Meyer pada tahun 2015 berjudul "Computerizing Exams: The Michigan Tech Testing Center". Penelitian ini membahas tentang Universitas seperti Brigham Young menawarkan fasilitas pusat untuk pengujian komputerisasi . Michigan Technological University mengikuti model ini dengan pembentukan Michigan Tech Testing Center ( MTTC) pada tahun 2012. Pusat ini 
menciptakan ruang yang mendukung ujian fleksibel, integritas yang tinggi untuk ujian komputerisasi. Makalah ini berfokus pada uji coba dari sebuah spreadsheet lab praktek menggunakan berkas pengajuan melalui kanvas dan Jotform. [3]

4. Penelitian yang dilakukan oleh Douglas Cohen dari State University of New York Institute of Technology, New York pada tahun 2014 yang berjudul "Design and Implement a Photo Gallery website for Snapshots of Resettlement: A Digital Showcase of Images and Stories of Resettled Refugees in Utica, NY'. Penelitian ini menjelaskan tentang ingin dibuatnya galeri foto online dari kejadian di pemukiman Bhutanese-Nepali dan para pengungsi yang menjadi gagasan nya. JotForm menjadi media untuk mensubmit foto yang dimiliki dan memiliki fungsi yang terkait dengan penelitian. JotForm direkomendasikan untuk pengajuan dalam memberikan hasil foto tersebut. [4]

5. Penelitian yang dilakukan oleh Håkan Eftring dari The Helen Hamlyn Centre for Design at the Royal College of Art, London, UK pada tahun 2011 yang berjudul "A model for an inclusive healthcare information system". Penelitian ini menjelaskan organisasi kesehatan seperti rumah sakit berkomunikasi baik secara umum dan informasi pribadi kepada warga. Informasi pribadi seperti pemberitahuan janji medis yang biasanya masih dikirim melalui pos biasa, sehingga dibuatlah form untuk informasi yang dapat diakses. Aplikasi JotForm digunakan sebagai media pembangunan form untuk menerima informasi dari masyarakat. Dan ini bisa menjadi pemberitahuan janji medis untuk pertemuan dan pemeriksaan atau informasi lainnya. [5]

6. Penelitian yang dilakukan oleh Paul Dervan dari Institute of Technology, Blanchardstown, Dublin pada tahun 2014 yang berjudul "Enhancing In-class Student Engagement Using Socrative (an Online Student Response System): AReport". Penelitian ini menjelaskan tentang Student Response System (SRS) yang merupakan sistem elektronik yang memungkinkan siswa untuk memberikan umpan balik dan tanggapan terhadap pertanyaan dan kuis selama kuliah menggunakan instrumen survei yang mengandung pertanyaan penulis yang dihasilkan dan menggunakan aplikasi JotForm secara online. [6]

7. Penelitian yang dilakukan oleh Esther Perales, Elisabet Chorro, Valentín Viqueira, Francisco M. Martínez Verdu dari University of Alicante (SPAIN) pada tahun 2012 yang berjudul "EVALUATION OF ONLINE TOOLS AS DIDACTIC RESOURCE IN THE UNIVERSITY EDUCATION". Penelitian ini menjelaskan tentang Alat yang digunakan untuk mengumpulkan informasi adalah kuesioner. Kuesioner ini mengevaluasi untuk berbeda aspek saja: pendapat umum, kualitas informasi yang diterima, kepuasan tentang metodologi yang diikuti dan kesadaran kritis siswa. Desain kuesioner ini sangat penting untuk mendapatkan informasi yang meyakinkan tentang metodologi mengikuti kursus. Kuesioner dikembangkan menggunakan alat online yaitu JotForm. [7]

8. Penelitian yang dilakukan oleh Stephen B. Gilbert, Stephen B. Blessing dan Enruo Guo dari International Journal of Artificial Intelligence in Education pada tahun 2015 yang berjudul "Authoring Effective Embedded Tutors: An Overview of the Extensible Problem Specific Tutor (xPST) System". Penelitian ini menjelaskan tentang Extensible Problem Specific Tutor (xPST) memungkinkan penulis yang bukan ilmuwan kognitif, bukan programmer untuk dengan cepat menciptakan sebuah bimbingan belajar yang cerdas sistem yang menyediakan instruksi mirip dengan tutor model tracing. Menggunakan pendekatan konten kustom ketika membuat tutor statistik, disebut xSTAT, menggunakan Web xPST. Penulis menggunakan JotForm, web sederhana bentuk penciptaan alat, untuk menyelesaikan sebuah masalah. [8]

9. Penelitian yang dilakukan oleh Karina Lucia Díaz Arrunategui, dari Universitat Politecnica De Catalunya pada tahun 2015 yang berjudul "External services integration for internal usage of an organization, using Google App Script". Penelitian ini menjelaskan tentang memilih solusi perangkat lunak yang sudah ada dan memberikan baru fitur serta mengintegrasikannya dengan layanan pihak ketiga, mempertahankan filosofi freeware itu sejak awal. Tujuan utama, tidak memperpanjang pengembangan inti aplikasi (yang spreadsheet) tetapi untuk meningkatkan kemampuannya untuk berkomunikasi dengan 
aplikasi dan layanan lain dan untuk menyatukan semua intelijen bisnis dan membiarkan aliran data. Bentuk JotForm dimasukan di Google sebagai tanggapan pengguna dalam lembar tertentu. Lembar ini memiliki script lain yang terikat untuk itu yang memeriksa apakah kesempatan yang ada dilembaran primer dan mendorong perubahan kepada mereka. [9]

10. Penelitian ini dilakukan oleh Francisco Javier Delgado Cepeda dan Full Profesor dari Monterrey Institute of Technology and Higher Education México pada tahun 2016 berjudul "Widget Based Learning in Math and Physics Undergraduate Courses as Blended Learning Approach, Athens: ATINER'S Conference Paper Series, No: EDU2015-1827”. Penelitian ini berisikan pengembangan program edukatif yang disajikan didasarkan pada situs mobile dibangun di Weebly mengintegrasikan program yang terlibat, kegiatan berbasis widget (widget, didaktik panduan dan usulan widget untuk kegiatan konstruksi oleh siswa) dan tutorial. Situs ini mencakup bentuk dirancang dengan Jotform untuk mengambil informasi dan gambar. Penelitian ini terintegrasi dengan Google Drive sebagai repositori. Interaksi dan alat-alat yang terlibat, sehingga sebagai tujuan dijelaskan secara menyeluruh. Masingmasing berisi: widget, yang didaktik panduan atau kuesioner, bentuk pencarian informasi dan kegiatan terkait untuk membangun widget. [10]

\section{METODE PENELITIAN}

Berikut adalah tahapan yang digunakan dalam penyusunan penelitian ini dengan menggunakan Metode Pengumpulan data.

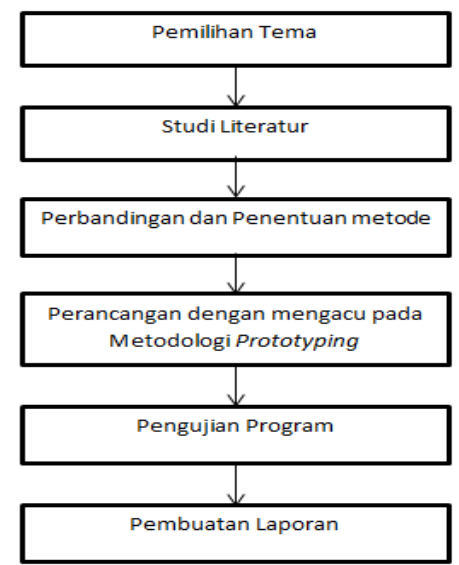

Gambar 2. Tahapan Penyusunan Penelitian

Keterangan :

1. Memilih dan menentukan terlebih dahulu permasalahan atau tema penelitian yang akan diambil.

2. Studi Literatur, metode yang digunakan mendapatkan data dengan cara melihat, membaca, serta mengembangkan informasi yang berkaitan dengan masalah yang dibicarakan sebagai referensi serta penunjang penelitian.

3. Perbandingan antar metode, membandingan antar metode JotForm guna mendapatkan motode yang tepat untuk dapat diimplementasikanpada proses pembuatan aplikasi.

4. Pengguna suatu metode perancangan sistem yang tepat dan disesuaikan dengan permasalahan dan aplikasi yang dibangun. Metodologi yang digunakan dalam perancangan program ini adalah metode prototyping dengan penyusunan penelitian ini dengan menggunakan Metode Pengumpulan data.

5. Pengujian program adalah tahapan yang dilakukan untuk validitas dan reliabilitas pada program yang dibuat

6. Laporan ditulis dalam bentuk dokumen setelah semua penelitian terselesaikan. 


\section{HASIL DAN PEMBAHASAN}

\subsection{Analisa Permasalahan}

Melihat pada sistem ZFord yang telah terapkan, terdapatnya permasalahanpermasalahan yang dihadapi. Permasalahan yang dihadapi dalam pelayanan perihal request pengambilan hasil donasi yaitu sistem pengambilan hasil donasi yang diajukan oleh users kepada admin masih menggunakan cara-cara lama dalam melakukannya yaitu masih mengirimkan email pribadi kepada admin, sehingga data akan sulit terkontrol apabila banyak users yang request, kemungkinan terjadinya human error saat melakukan proses input format data-data yang ingin mengajukan request pengambilan hasil donasi, request menggunakan email pribadi dapat menghabiskan banyak waktu dikarenakan harus membalas banyak permintaan yang ingin mengambil hasil donasinya. Format data perihal request pengambilan donasi ini akan berbeda-beda setiap usersnya, sangat tidak efektifnya apabila selamanya semua users yang ingin request selalu menggunakan email pribadi. Dan karena sewaktu-waktu admin akan berubah, maka kemungkinan users akan salah mengirim email kepada orang yang tidak lagi menjadi admin perihal request ini. Sehingga permasalahan permintaan disajikan dalam bentuk form online dengan adanya form online users dapat mengaksesnya dimana pun dan kapan pun dan format request akan sama.

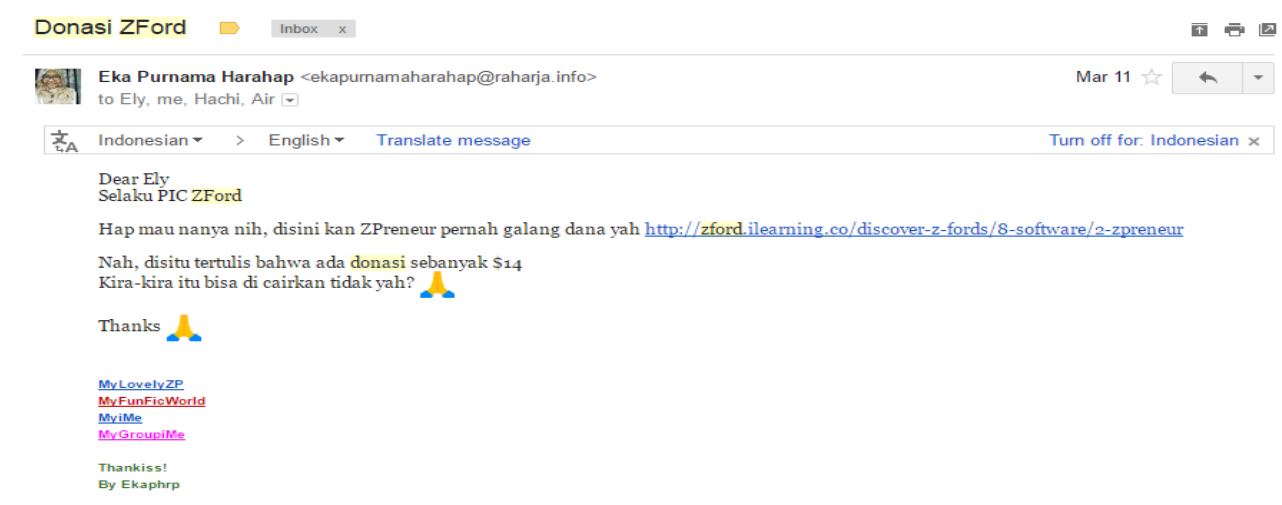

Gambar 3. Salah satu permasalahan yang dihadapi

Gambar diatas adalah gambar dimana users yang ingin request untuk mengambil hasil donasi nya salah dalam mengirim email, dikarenakan admin yang sudah berganti tetapi users tidak mengetahui nya. Maka dengan begitu admin perlu menjelaskan kembali perihal admin baru dan users harus request kembali, hal itu menyebabkan lamanya penanganan dalam pengambilan hasil donasinya.

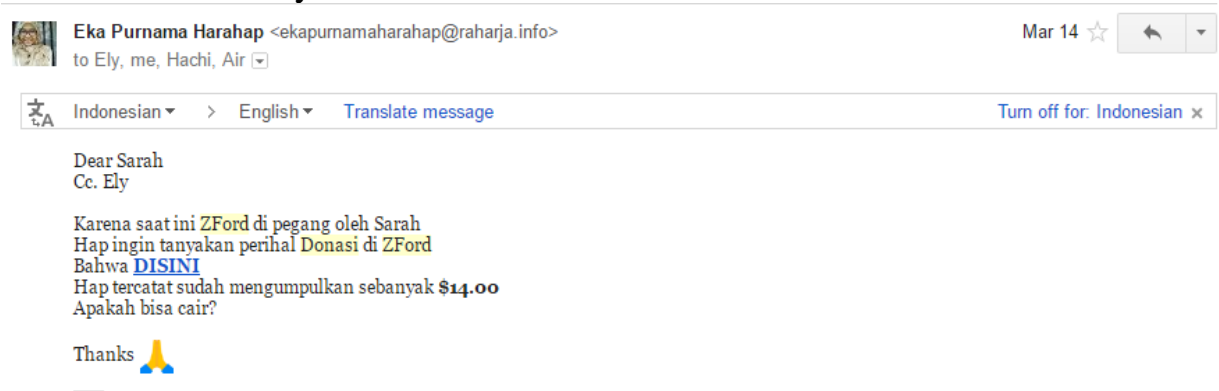

Gambar 4. Users request kembali 
Pada gambar 4 tersebut yaitu saat sebelumnya users salah mengirim email ke admin sebelumnya, dan ia harus request ulang ke admin baru. Maka akan banyak pembicaraan melalui email tersebut sehingga akan lama dalam penanganan.

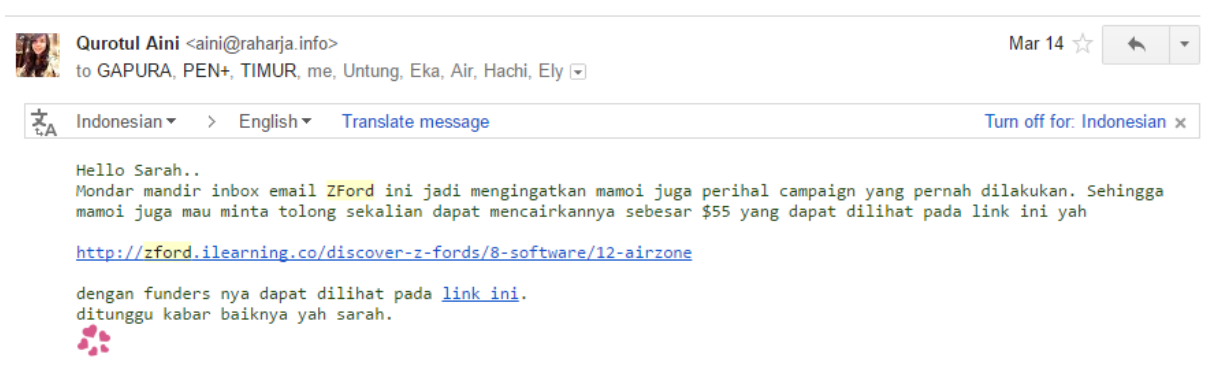

Gambar 5. Request dengan format data yang berbeda setiap users

Pada gambar di atas menjelaskan perihal request dengan format yang berbeda-beda setiap users nya, sehingga data yang diterima admin tidak jelas, tidak rapi dan tidak lengkap sesuai dengan kebutuhan untuk pengecekan.

Dari ketiga gambar dan penjelasan diatas terbukti bahwa dalam request pengambilan donasi masih banyak kesalahan-kesalahan yang dihadapi. Dan proses pelayanan pengambilan hasil donasi untuk perihal request yang dilakukan oleh users ke bagian admin masih menerapkan 10 (sepuluh) langkah pada sistem lama seperti yang dijelaskan dalam usecase diagram dibawah ini :

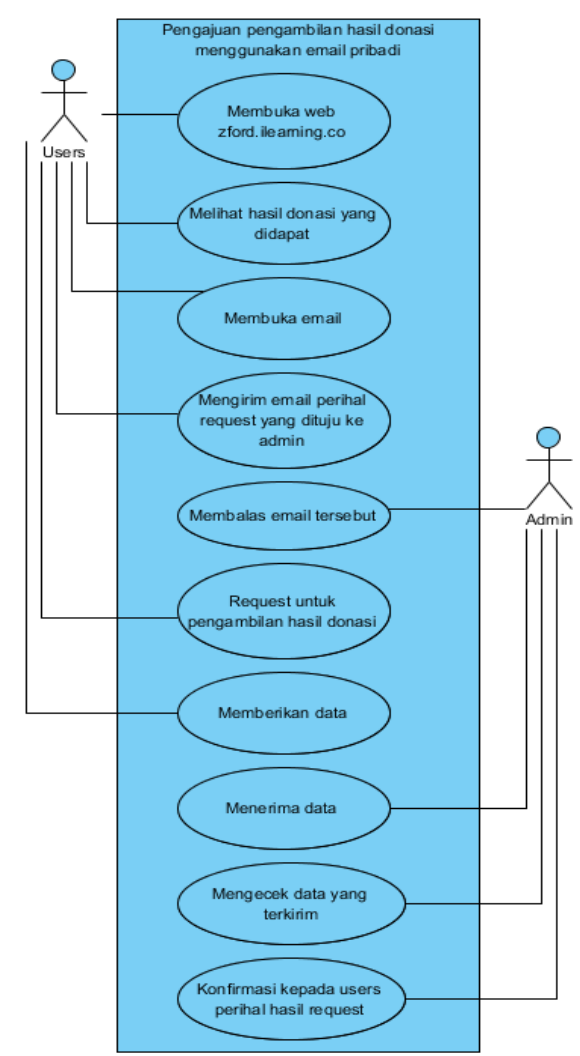

Gambar 6. Usecase diagram pengajuan pengambilan hasil donasi menggunakan email pribadi

Gambar diatas menjelaskan tentang 10 (sepuluh) langkah proses pengajuan pengambilan hasil donasi menggunakan email pribadi yang masih harus dilakukan oleh users saat ingin mengajukan permintaannya kepada admin untuk pengambilan hasil donasi. 


\subsection{Pemecahan Masalah}

Untuk mengatasi permasalahan dalam pelayanan untuk pengambilan hasil donasi yang masih request menggunakan email pribadi harus segera diatasi.

Maka dari itu di ciptakanlah aplikasi Form Online menggunakan aplikasi JotForm dimana dengan sistem ini siapa pun dapat menginputkan data untuk mengambil hasil donasinya. Pembuatan aplikasi ini menggunakan aplikasi JotForm. Dengan aplikasi ini proses request pengambilan hasil donasi dapat lebih efektif dan efisien, serta dapat mengurangi kesalahankesalahan penerimaan data. Aplikasi ini juga sebagai suatu inovasi baru dalam sistem yang terdapat di ZFord. Dengan adanya aplikasi ini di harapkan dapat mempermudah pengguna dalam request pengambilan hasil donasinya.

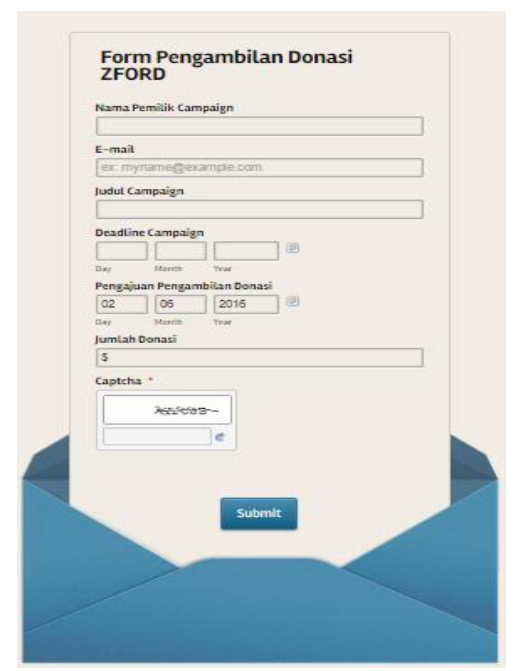

Gambar 7. Rancangan form online menggunakan JotForm

Tampak pada Gambar 7. merupakan rancangan form online untuk pengambilan hasil donasi menggunakan aplikasi JotForm. Request dengan menggunakan form yang telah disediakan oleh admin untuk pengguna dapat mempermudah pengguna dalam merequest karena form sudah terdapat di website tesebut dan sudah dapat diakses secara online. Untuk mengoptimalkan sistem yang sudah di terapkan di perlukan aplikasi-aplikasi pendukung pada sistem yang terdapat di ZFord tersebut yang dapat di gunakan untuk proses pengambilan hasil donasi, oleh sebab itu maka di buatlah pemanfaatan aplikasi JotForm sebagai media request pengambilan donasi pada sistem ZFord.

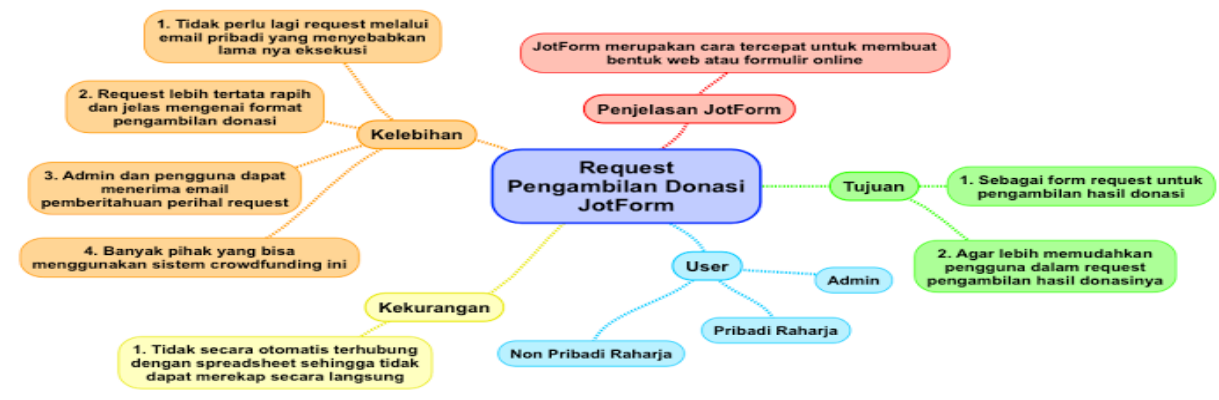

Gambar 8. Mind Mapping request pengambilan donasi menggunakan JotForm 
Tampak pada gambar diatas adalah Mind Mapping request pengambilan donasi menggunakan JotForm. JotForm merupakan cara tercepat untuk membuat bentuk web atau formulir online. Tujuan dibuatnya aplikasi ini yaitu sebagai form request untuk pengambilan hasil donasi, agar lebih memudahkan pengguna dalam request pengambilan hasil donasinya. Kelebihan dengan adanya form request secara online ini yaitu tidak perlu lagi request melalui email pribadi yang menyebabkan lamanya eksekusi (penanganan), request lebih tertata rapih dan jelas mengenai format pengambilan donasi, admin dan pengguna dapat menerima email pemberitahuan perihal request, banyak pihak yang bisa menggunakan sistem crowdfunding ini. Kekurangan menggunakan aplikasi JotForm ini yaitu tidak secara otomatis terhubung dengan spreadsheet, melainkan kita harus lihat diwebsite JotFom tersebut. User pada website ini yaitu Admin, Pribadi Raharja, dan Non Pribadi Raharja. Lima point mind mapping tersebut diambil berdasarkan fakta yang sesungguhnya yang terjadi pada form request pengambilan donasi menggunakan JotForm hasil dari penelitian yang dilakukan oleh peneliti.

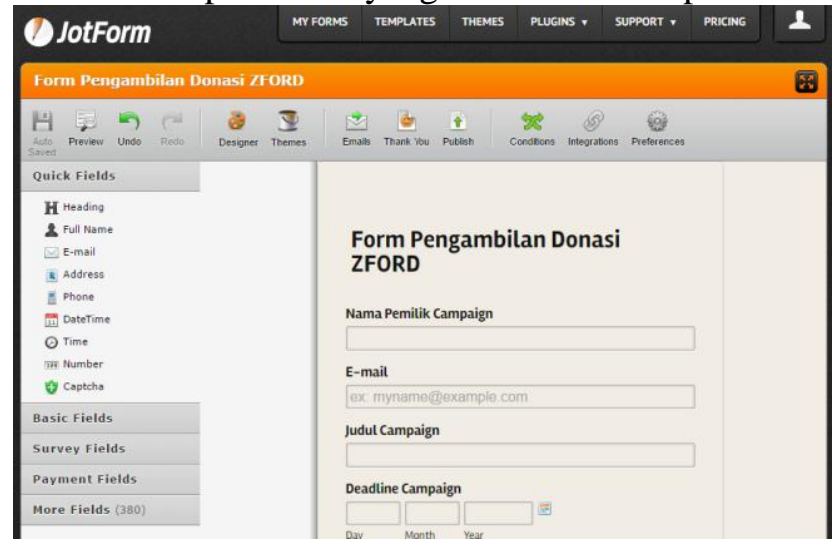

Gambar 9. Form Pengambilan Donasi ZFord pada JotForm

Pada Gambar 9. diatas merupakan tampilan pada website JotForm dimana terdapatnya form yang telah dibuat oleh admin. Form bisa dibuka kembali ataupun bisa diedit kembali jika kita sudah mempunyai akun di website tersebut. Dan pada gambar tersebut juga menerangkan betapa mudahnya apabila kita ingin membuat form dikarenakan sudah tersedianya field-field yang langsung dapat di drag and drop, sehingga memudahkan para penggunanya. Pemberitahuan notifications email juga dapat diatur tanpa harus menggunakan kodingan program. Dan dapat di publish diberbagai platforms yang tersedia.

Berikut merupakan grafik diagram Pie perbandingan pembaharuan sistem request pengambilan donasi menggunakan metode dengan request melalui email pribadi dengan request menggunakan form online.

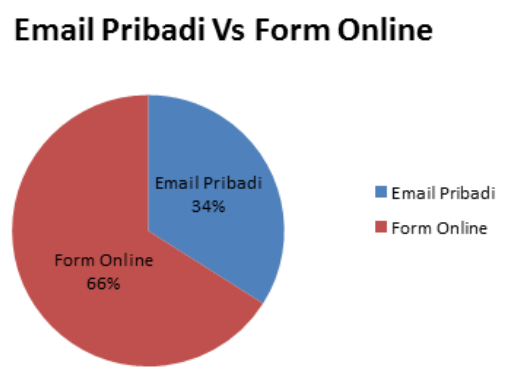

Gambar 10. Graph diagram Pie pembaharuan sistem request pengambilan donasi

Tampak pada gambar diatas merupakan perbandingan request pengambilan donasi menggunakan email pribadi dan form online, berdasarkan hasil survey yang dilakukan pada 50 
orang di gambarkan dalam sebuah grafik atau diagram Pie seperti yang terlihat pada gambar 10 diatas, pada grafik tersebut terlihat persentase minat pengguna dalam merequest pengambilan donasi menggunakan form online lebih besar dibanding dengan menggunakan email pribadi. Request dengan menggunakan sistem form online yang telah tersedia dalam website tersebut dapat memudahkan pengguna dalam mengisi form untuk pengambilan donasinya.

Dalam form tersebut sudah terdapatnya format untuk data apa saja yang diperlukan sehingga admin tidak perlu lagi bertanya perihal data-data yang pengguna.

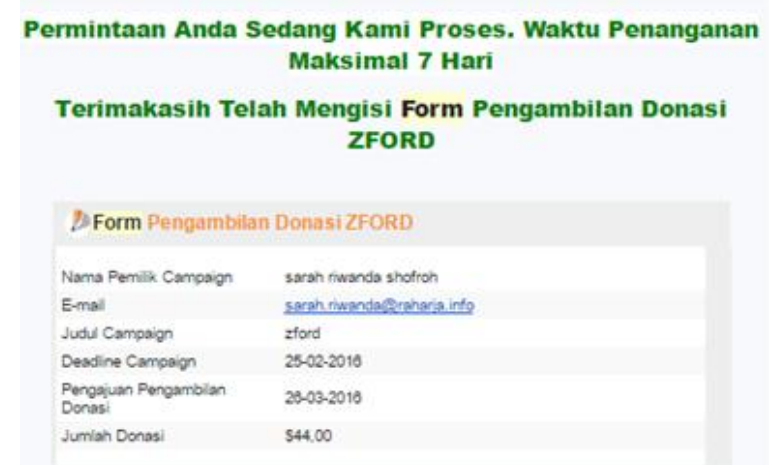

Gambar 11. Tampilan email yang akan diterima pengguna

Gambar diatas merupakan tampilan email yang akan diterima pengguna ketika sudah mengisi form online tersebut. Setelah mengisi form tersebut pengguna akan mendapatkan email pemberitahuan untuk menunggu hasil donasinya yang sedang diproses.

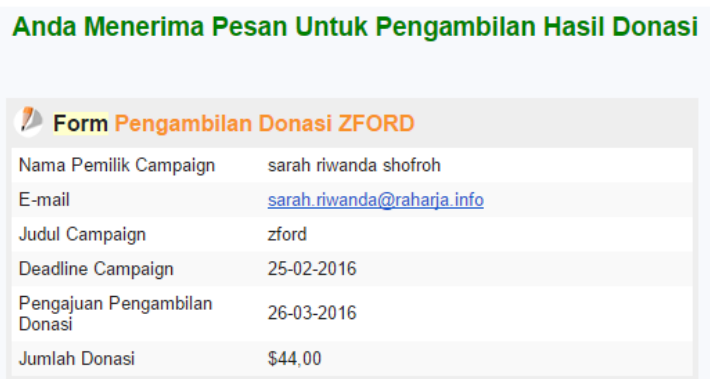

Gambar 12. Tampilan email yang akan diterima oleh Admin

Gambar diatas merupakan tampilan email yang akan diterima oleh admin ketika ada yang mengisi form pengambilan donasi. Setelah adanya email tersebut, admin langsung memproses untuk pencairan dana.

\subsection{Implementasi}

Menu Pengambilan donasi ZFord ini sudah diimplementasikan pada website zford.ilearning.co sebagai media pengambilan donasi secara cepat dan untuk meningkatkan kualitas pelayanan kepada para pengguna. Menu ini juga dapat diakses dan dilihat langsung pada website zford.ilearning.co

Form ini telah digunakan oleh beberapa pengguna untuk merequest hasil donasi yang didapatkannya. Admin dapat melihat siapa saja yang telah mengisi data untuk perihal request ini pada website JotForm. Data terdapat pada Menu Submission dimana hanya yang mempunyai akun tersebut yang dapat melihatnya. 


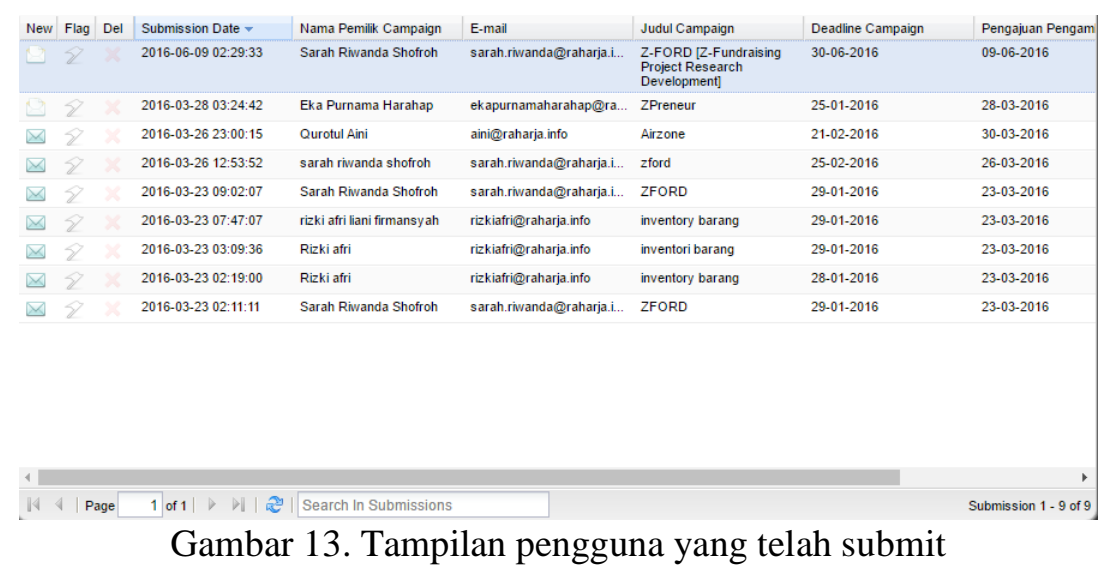

Pada gambar diatas merupakan tampilan pengguna yang telah mengisi data kemudian submit. Data akan terekam pada website JotForm. Data tersebut juga dapat di download, sehingga sangat memudahkan bagi pengguna JotForm.

\section{KESIMPULAN}

Berdasarkan dari hasil analisa dan studi kasus yang telah dilakukan maka pemanfaatan aplikasi JotForm sebagai media request pengambilan hasil donasi ini memang diperlukan guna meningkatkan kualitas dan efektifitas khususnya pada sistem ZFord sebagai salah satu website crowdfunding, yang menerapkan sistem maupun metode menggunakan aplikasi JotForm. Dimana semua aktifitas apabila users request pengambilan hasil donasinya dapat dilakukan menggunakan form online yang telah tersedia di web tersebut. Sehingga di buatlah rancangan aplikasi form online menggunakan JotForm sebagai salah satu media pendukung dalam perihal request apabila ada users yang ingin mengambil hasil donasinya dan sebagai media untuk membantu admin dalam mengecek data yang telah diisi oleh users tersebut. Serta dengan adanya aplikasi ini di harapkan dapat mengurangi pemakaian email yang akan menyebabkan lamanya proses penanganan. Karena aplikasi ini dapat dijalankan secara online, sehingga siapa pun dapat melihat, dan mengaksesnya dimana saja dan kapan saja. Sesuai dengan prinsipnya dengan adanya pembaharuan ini request bisa dilakukan dengan efektif dan dapat diakses dimana saja dan kapan saja.

\section{SARAN}

Model sederhana dapat menjelaskan beberapa hal yang lebih akurat, tetapi banyaknya kekurangan pada karya ilmiah ini karena tidak terlalu banyak yang dapat dijelaskan. Untuk penelitian selanjutnya pembuatan form online seperti ini dapat juga dilakukan dengan menggunakan google form ataupun form online lainnya.

Pada penelitian selanjutnya juga dapat dikembangkan pengujian untuk beberapa responden dan kembali memberikan kuesioner terhadap pelayanan pengambilan hasil donasi di ZFord, agar sistem dapat melakukan pembaharuan sesuai keinginan users.

\section{UCAPAN TERIMA KASIH}

Penulis mengucapkan terima kasih kepada STMIK Raharja yang telah memberi dukungan finansial dan fasilitas terhadap penelitian ini. 


\section{DAFTAR PUSTAKA}

[1 ]. H Amee, C Isaac. "I HAVE RESERVATIONS: The Design and Implementation of an Online Library Instruction Form for University Faculty", Wingate University : North Carolina, United States, 2015.

[2]. DV Birolini, S Rasslan, EM Utiyama. "Unintentionally retained foreign bodies after surgical procedures. Analysis of 4547 cases". Universidade de São Paulo (HCFMUSP) : SP, Brasil, 2016.

[3 ]. AJ Kemppainen, GL Hein, MR Meyer. "Computerizing Exams: The Michigan Tech Testing Center", 2015.

[4 ]. Cohen, Douglas. "Design and Implement a Photo Gallery website for Snapshots of Resettlement: A Digital Showcase of Images and Stories of Resettled Refugees in Utica, $N Y$ ', State University of New York Institute of Technology : New York, 2014.

[5 ]. Eftring, Håkan. "A model for an inclusive healthcare information system", The Helen Hamlyn Centre for Design at the Royal College of Art : London, UK, 2011.

[6 ]. Dervan, Paul. "Enhancing In-class Student Engagement Using Socrative (an Online Student Response System): A Report", Institute of Technology : Blanchardstown, Dublin, 2014.

[7 ]. Perales, Esther., Chorro, Elisabet., Viqueira, Valentín., dan Martínez Verdú, F. M. "Evaluation of online tools as didactic resource in the university education", University of Alicante : SPAIN, 2012.

[8 ]. Gilbert, Stephen B., Blessing, Stephen B., and Guo, Enruo. "Authoring Effective Embedded Tutors: An Overview of the Extensible Problem Specific Tutor (xPST) System", International Journal of Artificial Intelligence in Education 25.3 : 428-454, 2015.

[9 ]. Diaz Arrunategui, Karina Lucia. "External services integration for internal usage of an organization, using Google App Script", Universitat Politecnica De Catalunya, 2015.

[10 ]. Cepeda, Francisco Javier Delgado, dan Profesor, Full. "Widget Based Learning in Math and Physics Undergraduate Courses as Blended Learning Approach, Athens: ATINER'S Conference Paper Series, No: EDU2015-1827", Monterrey Institute of Technology and Higher Education México, 2016. 